\title{
Effect of Functionalized Carbon Nanofibers with Carboxylic Function Group on the Removal of Zinc from water
}

\author{
Muataz Ali Atieh
}

\begin{abstract}
This study was carried out to evaluate the environmental application of modified and non-modified carbon nanofiber through the experiment removal of zinc from water. Results of the study showed that raw (non-modified) CNFs have very poor efficiency in removing zinc from water by conventional adsorption mechanism. However, when CNFs was modified with carboxylic group, a significant improvement in the zinc removal efficiency was observed. Five independent variables including $\mathrm{pH}$, CNFs dosage, contact time, agitation speed and initial concentration were carried out to determine the influence of these parameters on the adsorption capacity of the zinc from water. Results of the study showed that, $97 \%$ of zinc was removed by using $\mathrm{COOH}-\mathrm{CNFs}$ at $\mathrm{pH} 7,150 \mathrm{rpm}$, and 2 hours. These high removal efficiencies were likely attributed to the strong affinity of zinc to the physical and chemical properties of the CNFs. For results analysis, adsorption isotherms have been used in order to study the kinetics of the adsorption behavior and to determine the adsorption capacity of the absorbents.
\end{abstract}

Index Terms-Carbon nanofiber, zinc removal, functionlization and adsorption isotherms.

\section{INTRODUCTION}

The pollution of water resources due to the disposal of heavy metals has been causing worldwide concern. The main sources of these metals are mining, metallurgical, chemical manufacturing, tannery, battery manufacturing industries, fossil fuel, the modern chemical industry is based largely on catalysts, many of which are metals or metal compounds, production of plastics, such as polyvinyl chloride, involves the use of metal compounds, particularly as heat stabilizers etc . The effects of heavy metals such as copper, zinc, zinc, mercury, chromium and cadmium on human health have been investigated extensively. Zinc is one of these heavy metals which consider as toxic materials if it exceeding the acceptable level. Zinc oxide is widely used as a white pigment in paints, and as a catalyst in the manufacture of rubber [1]. Zinc waste causes environmental and public health problems. Although humans can handle proportionally large concentrations of zinc, excess zinc can be harmful. The free zinc ion in solution is highly toxic to plants, invertebrates, and even vertebrate fish.

Manuscript received March 16, 2011.

Muataz Ali Atieh, Chemical Engineering Department, Center of Research Excellence in Nanotechnology (CENT), King Fahd University of Petroleum \& Minerals, Dhahran 31261, Saudi Arabia

TEL: 0096638606182 , FAX:0096638604234

Email: motazali@kfupm.edu.sa
Excess amount of zinc may cause zinc toxicity which zincs to a severe haemolytic anomie, liver and kidney damages; vomiting and diarrhea are possible symptoms. The consumption of fruit juices stored in galvanized cans has resulted in mass parrot poisonings with zinc [3]. Many methods have been developed and used to remove metal ions from wastewater such as granulated activated Carbon [4], fly ash [5], peat [6], recycled alum sludge [7], peanut hulls [8], resins [9], kaolinite [10], manganese oxides [11], zeolite [12], biomaterials $[13,14]$. However, the removal efficiencies of metal ions of these adsorbents were low. Therefore, researchers carried out investigation for new promising adsorbents [15].Nanofibers shown if figure 1consist of the graphite sheet completely arranged in various orientations. One of the most outstanding features of these structures presence of a plenty of sides which in turn make sites, with readiness accessible to chemical or physical interaction, especially adsorption. From electronic microscopy studies, it was possible to define sequence of the events zincing to the formation of carbon nanofibers.

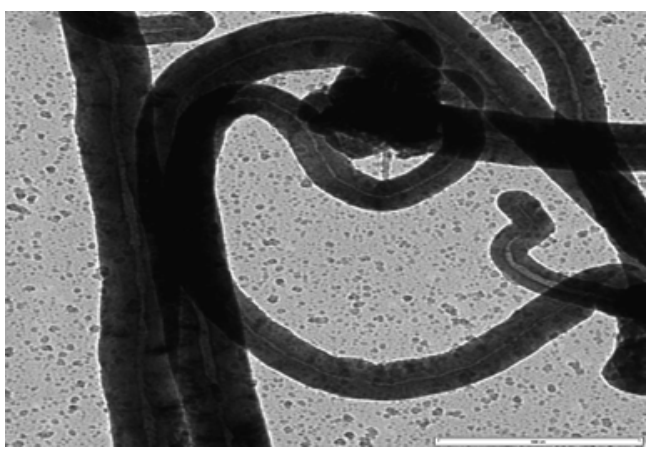

Figure.1: TEM images of carbon nanofiber Carbon nanofibers change from 5 to several hundred microns on length and between 100-300 $\mathrm{nm}$ in diameter [16].

\section{METHOLOGY}

\section{Oxidation of CNFs}

Carbon Nanofibers (CNFs) were purchased from Nanostructured \& Amorphous Materials, Inc. USA. The Purity of raw CNFs is $>95 \%$, its outside diameters are $100-200 \mathrm{~nm}$ while the length reach up to $30 \mathrm{um}$. Three hundred $\mathrm{ml}$ of a concentrated nitric acid of AnalaR (69\%) are added to $2 \mathrm{~g}$ of as-received CNFs. The mixture is refluxed for $48 \mathrm{~h}$ at $120^{\circ} \mathrm{C}$. After cooling to room temperature, the reaction mixture is diluted with $500 \mathrm{ml}$ of deionised water and then vacuum-filtered through a filter paper $(3 \mu \mathrm{m}$ porosity). This washing operation is repeated until the $\mathrm{pH}$ 
become same as deionsed water $\mathrm{pH}$ and is followed by drying in a vacuum oven at $100^{\circ} \mathrm{C}$. Such conditions zinc to remove the catalysts from carbon nanofibers and opening the tube caps as well as the formation of holes in the sidewalls, followed by an oxidative etching along the walls with the concomitant release of carbon dioxide. This less vigorous conditions, minimized the shortening of the tubes and the chemical modification is then limited mostly to the opening of the tube caps and the formation of functional groups at defect sites along the sidewalls. The final products are nanotube fragments whose ends and sidewalls are decorated with a various oxygen containing groups (mainly carboxyl groups). Moreover, the percentage of carboxylic functions on the oxidized CNFs surface does not exceed $4 \%$ in the best cases, which corresponds to the percentage of CNFs structural defects [17].

\section{Preparing the stock solution}

The stock solution was prepared by adding $2 \mathrm{~mL}$ of zinc from zinc standard solution of concentration, $1000 \mathrm{mg} / \mathrm{L}$ into $2 \mathrm{~L}$ volumetric flask. The $\mathrm{pH}$ of the stock solution was adjusted by using 1.0 M Nitric Acid or 1.0 M NaOH. Finally buffer solutions were added to maintain the $\mathrm{pH}$ constant during the experimental.

\section{Batch Mode Adsorption Experiment}

The experiment of the batch mode adsorption was conducted at room temperature to study the effect of initial solution $\mathrm{pH}, \mathrm{CNT}$ dosage, contact time and agitation speed on the adsorption of zinc ions. Each experiment was conducted in volumetric flask and the initial and final concentrations of zinc were analyzed by using Inductively Coupled Plasma (ICP).

The amount of zinc removed was determined by the difference of the initial concentration $(\mathrm{Ci})$ and the final concentration $(\mathrm{Cf})$. The percentage removed of zinc ions from the solution was calculated using the following relationship:

$$
\% \operatorname{Re} \text { moval }=\frac{C_{i}-C_{f}}{C_{i}} \times 100
$$

The metal adsorption capacity (qe) was calculated by the following equation:

$$
\mathrm{q}_{\mathrm{e}}(\mathrm{mg} / \mathrm{g})=\frac{C_{i}-C_{e}}{M_{s}} \times V
$$

Where:

$\mathrm{V}=$ volume of the solution $(\mathrm{L})$

$\mathrm{M}_{\mathrm{s}}=$ weight of adsorbent (g)

\section{Adsorption isotherm models}

The experimental data for zinc adsorption onto MCNTs could be approximated by the linear forms of both Langmuir isotherm models:

$$
\frac{C_{e}}{Q_{e}}=\frac{1}{q_{m} K}+\frac{C_{e}}{q_{m}}
$$

Where:

$\mathrm{Q}_{\mathrm{e}}=$ the adsorption density (mg of adsorbate per $\mathrm{g}$ of adsorbent)

$\mathrm{Ce}=$ the concentration of adsorbate in solution $(\mathrm{mg} / \mathrm{l})$.

$\mathrm{K}=$ the empirical constants dependent on several environmental factors.

\section{IIIRESULTS AND DISSCUTION}

\section{FTIR Characterization}

FTIR spectra from the CNFs shows a two peak at $\sim 3225$ $\mathrm{cm}-1$ and $2974 \mathrm{~cm}-1$ which refers to O-H stretch of hydroxyl group (Figure 2) which can be ascribed to the oscillation of carboxyl groups. The IR spectra of oxidized CNFs shows four major peaks, located at 3728, 3425, 2361 and $1560 \mathrm{~cm}^{-1}$. The peak at $3728 \mathrm{~cm}^{-1}$ is attributed to free hydroxyl groups. The peak at $3225 \mathrm{~cm}^{-1}$ can be assigned to the $\mathrm{O}-\mathrm{H}$ stretch from carboxyl groups $(\mathrm{O}=\mathrm{C}-\mathrm{OH}$ and $\mathrm{C}-\mathrm{OH})$ while the peak at $2295 \mathrm{~cm}-1$ can be associated with the $\mathrm{O}-\mathrm{H}$ stretch from strongly hydrogen-bonded $-\mathrm{COOH}$. The peak at $1468 \mathrm{~cm}^{-1}$ is related to the carboxylate anion stretch mode. It should be noticed that the as-received CNFs were purified by the manufacturer and part of the catalytic metallic nanoparticles were possibly eliminated during the purification process cutting the nanotube cap.

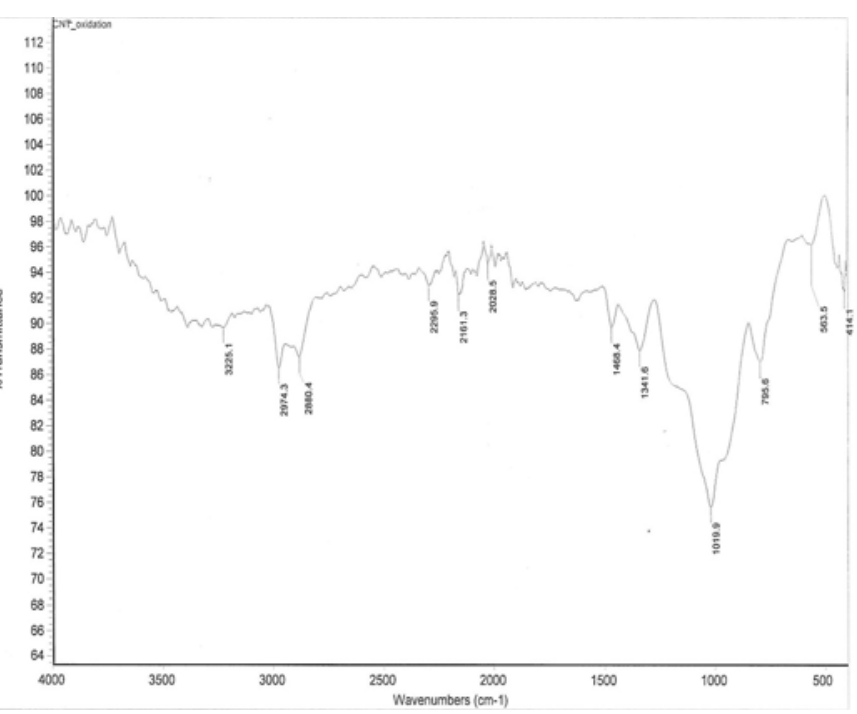

Figure 4: FTIR of Carbon Nanofibers (CNFs) modified with $\mathrm{COOH}$

\section{Effect of pH on the Removal of Zinc from Water}

The $\mathrm{pH}$ of aqueous solution is one of the major parameters that control the adsorption of ion at the solid-water interfaces. In addition to that it is affects the solubility of the metal ions, concentration of the counter ions on the functional groups of adsorbent and the degree of ionization of the adsorbate during the reaction. The removal of zinc by two types of adsorbents: modified (Oxidized) and non-modified CNFs with various $\mathrm{pHs}$ has been studied while the other parameters such as the contact time, agitation speed and the amount (dosage) of CNFs have fixed at $2 \mathrm{Hr}, 150 \mathrm{rpm}$ and $50 \mathrm{mg}$ respectively. The $\mathrm{pH}$ of these experiments were varied from 4-7. Figure 2 shows the effect of $\mathrm{pH}$ on the adsorption of zinc, which was used as a model of divalent metal ion on raw carbon nanofibers (R-CNFs) and modified carbon nanofibers(M-CNFs). Maximum removal of $\mathrm{Zn}$ species was achieved at $\mathrm{pH} 4$. Its clearly showing that, $20 \%$ removal of Zinc was achieved by Raw CNFs while $90 \%$ of the removal of zinc was achieved by Modified CNFs with carboxylic function groups as shown in figure 3. The carboxylic $(-\mathrm{COOH})$ function groups increase the adsorption rate of the CNFs due to the strong interaction between the ion positive charges and functional groups negative charges. 


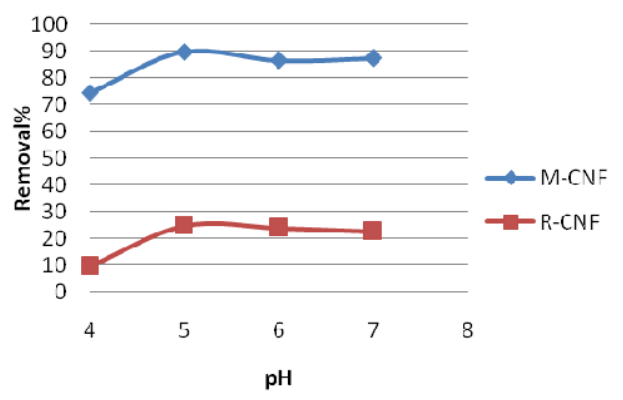

Figure 3: Effect of Modified Carbon Nanofibers (M-CNF) and Raw Carbon Nanofibers(R-CNF) on the removal of Zinc at different $\mathrm{pH}$

\section{Effect of Contact Time}

Small increase on the removal of zinc from water was observed by increasing the time from 10 -220 minutes when modified CNFs was used while a significant increase on the adsorption of zinc was achieved when raw CNFs was used. Figure 4 shows the amount of zinc adsorbed onto both raw Carbon Nanofibers (R-CNFs) and modified Carbon Nanofibers (M-CNfs) at different time range from 10-220 minutes while all other parameters such as the $\mathrm{pH}$, Dosage of CNFs and agitation speed were fixed at $7,50 \mathrm{mg}$ and 150 rpm.

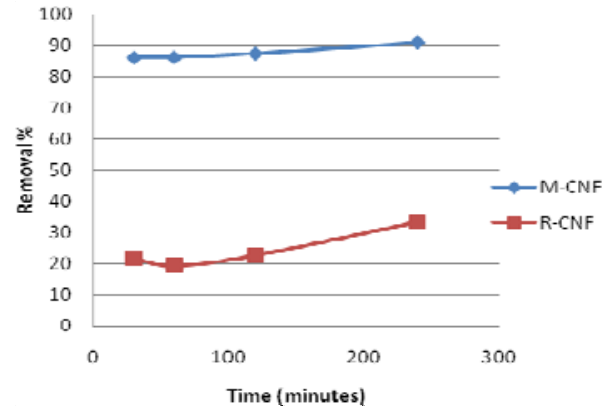

Figure 4: The effect of time on percentage removal of zinc at $150 \mathrm{rpm}, \mathrm{pH} 7$ and $50 \mathrm{mg}$

\section{Effect of the CNFs dosage}

The dependence of zinc sorption on dose was studied by varying the amount of adsorbents of R-CNFs and M-CNFs from 50 to 150 from, while keeping other parameters $\mathrm{pH}$, agitation speed and contact time constant at 7, $150 \mathrm{rpm}$ and 2 hours respectively. Figure 5 represent the zinc removal efficiency for $\mathrm{pH}$ 6. From the figure it can observed that, 97\% of zinc was removed when $150 \mathrm{mg}$. This suggests that after the solution reaches saturated phase, the maximum adsorption sets in and hence the amount of ions bound to the adsorbent and the amount of free ions remain constant even further addition of dose of adsorbent.

\section{Effect of Agitation Speed}

The effect of agitation speed on removal efficiency of zinc was studied by varying the speed of agitation from 50 to 200 rpm, while keeping the optimum dose of adsorbents (150 $\mathrm{mg}$ ), optimum $\mathrm{pH}(\mathrm{pH} \mathrm{7})$ and contact time at $2 \mathrm{hr}$ constant. As can be seen from Figure 6 the zinc removal efficient generally increased with increasing agitation speed. The removal efficiency of M-CNFs adsorbent increased from $\sim 70 \%$ to $\sim 90 \%$ when agitation speed increased from $100 \mathrm{rpm}$ to $200 \mathrm{rpm}$. This is due to the fact that, the increase of agitation speed, improves the diffusion of zinc ions towards the surface of the CNFs.

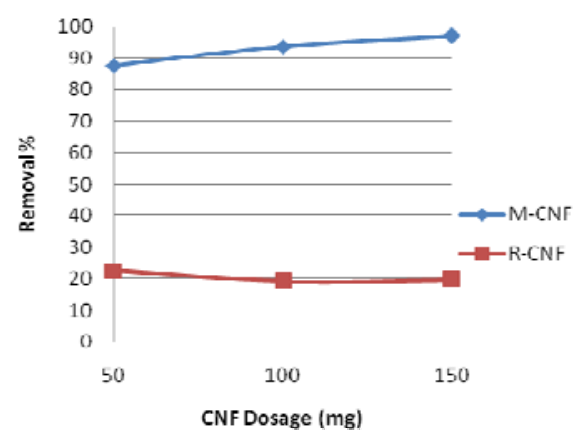

Figure 5: The effect of dosage of CNFs on percentage removal of zinc at 150 rpm, pH 7 and $2 \mathrm{Hr}$.

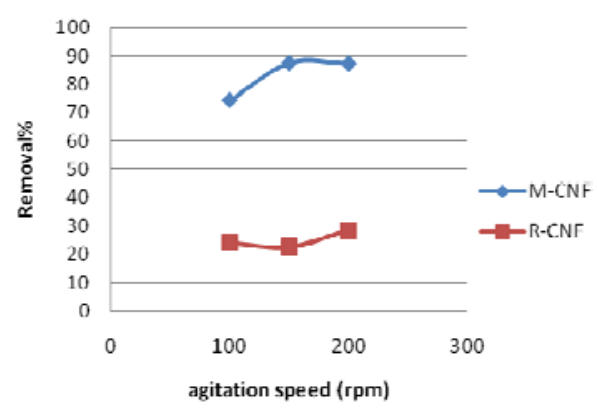

Figure 6: The effect of agitation speed on percentage removal of zinc at $\mathrm{pH} 7$ and $2 \mathrm{Hr}$.

\section{Effect of Zinc Concentration}

Various concentrations of $\mathrm{Zn}$ solutions $(1,1.5,2) \mathrm{ppm}$ were used to study their effect on the percentage removal of $\mathrm{Zn}$ keeping the other parameters $\mathrm{pH}$ (7), agitation speed(150rpm), contact time (2hrs) and CNF's dosage fixed. Figure 7 shows the percentage removal of zinc at different concentration. It is clearly shown that the percentage removal of zinc decreases by increasing the concentration using M-CNFs, while there is no effect R-CNF's on the removal of zinc at different concentration.

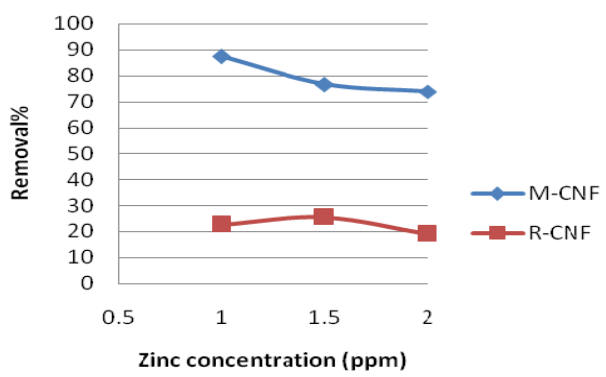

Figure 7: The effect of zinc concentration on percentage removal of zinc at $150 \mathrm{rpm}, \mathrm{pH} 7$ and $2 \mathrm{Hr}$.

\section{Adsorption Isotherm Models for Zinc}

The equilibrium adsorption is important in the design of adsorption systems. Equilibrium studies in adsorption indicate the capacity of the adsorbent during the treatment process. Taking into account that the percentage removal of zinc was highest at $\mathrm{pH} 7$, the condition was used to further optimize the adsorption process parameters. The equilibrium curve was modeled in Figure 8. The Langmuir model was used to describe the data derived from the adsorption of zinc over the entire parameters range studied. Based on Figure 8, the adsorption capacity (qmax) and adsorption intensity were determined from the slope and intercept of the graph respectively. Table 1 summarizes the results of both adsorption isothermal models. 


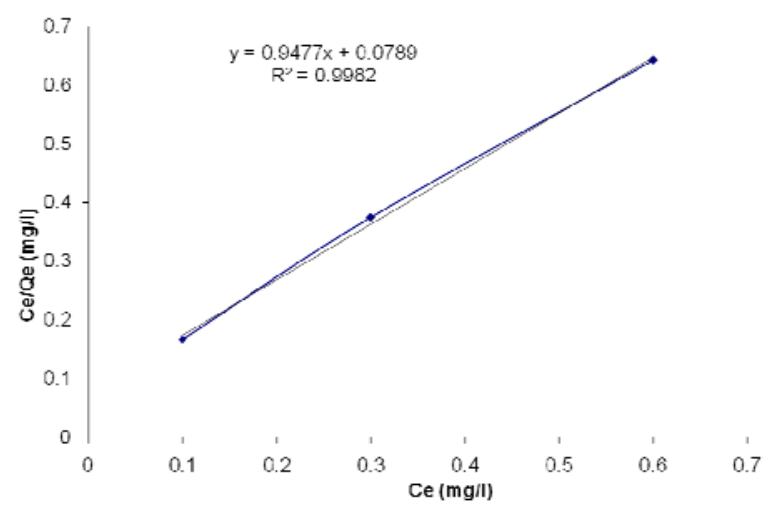

Figure 8: adsorption isotherm models for zinc Langmuir

Table 1: Parameters of Langmuir adsorption isotherm models for zinc

\begin{tabular}{|c|c|c|c|}
\hline \multirow{2}{*}{$\mathrm{pH}$} & \multicolumn{3}{|c|}{ Langmuir } \\
\cline { 2 - 4 } & $\mathrm{qmax}$ & $\mathrm{K}_{\mathrm{L}}$ & $\mathrm{R}^{2}$ \\
\hline 7 & 1.05 & 12.07 & 0.9982 \\
\hline
\end{tabular}

Langmuir Isotherm shows better fit model with higher correlation coefficient $(\mathrm{r} 2=0.9982)$. This is indicative of the applicability of monolayer coverage of zinc ions on the surface of the adsorbent due to its larger surface area. The good correlation coefficient of Langmuir isotherm also indicates that zinc ions strongly adsorbed to the surface of CNFs. Therefore, it is verified that CNFs have great potential to be a good adsorbent for the removal of zinc ions in water treatment.

\section{CONCLUSION}

The effect of Modified and non modified Carbon Nanofibers on the removal of zinc metal ions from water was studied. Carbon Nanofibers was found to be efficient for the adsorption of $\mathrm{Zn}$ in aqueous solution. The characterization of $\mathrm{Zn}$ uptake showed that, the zinc binding is dependent on initial $\mathrm{pH}$, agitation speed, amount of dosage, and contact time. Percentage uptake increased with an increased in $\mathrm{pH}$ from $\mathrm{pH} 4$ to $\mathrm{pH}$ 7. The optimum $\mathrm{pH}$ found in this study is $\mathrm{pH}$ 4 in which it gave $23 \%$ removal of $Z n$ ions by using R-CNFs and $90 \%$ of $Z n$ ions by using M-CNFs from aqueous solution. The percentage uptake increase slightly with an increase in agitation speed from 100 to $200 \mathrm{rpm}$. While the percent removal of $\mathrm{Zn}$ was observed to be optimal for higher dosage of CNTs, in which $150 \mathrm{mg}$ of M-CNFs contribute to $97 \%$ removal of $\mathrm{Zn}$.

\section{ACKNOWLEDGMENT}

The authors are grateful to the King Fahd University for Petroleum and Minerals (KFUPM) and Mr. Ali Abdul Salam Al-Ali for supporting and providing the laboratory facilities.

\section{REFERENCES}

[1] E. John "Zinc" An A-Z guide to the elements ,Oxford university press. UK. (2001)

[2] D. Robert. Handbook of Minerals as Nutritional Supplements. CRC Press. pp. 135, 155 (2004).

[3] G. F. Nordberg, B. Flower, M. Nordberg, L. Friberg. Handbook on the Toxicology of Metals, 3rd, Academic Press, 2007.

[4] M. Sekar, V. Sakthi and S. Rengaraj, Kinetics equilibrium adsorption study of zinc(II) onto activated carbon prepared from coconut shell, J. Colloid Interface Sci. 279 (2004), pp. 307-313).

[5] J. Ayala, F. Blanco, P. Garcia, P. Rodriguez and J. Sancho, Asturian fly ash as a heavy metals removal material, Fuel 77 (1998), pp. 1147-1154.

[6] Y. S. Ho and G. McKay, The sorption of zinc (II) ions on peat, Wat. Res. 33 (1999), pp. 578-584.

[7] W. Chu, Zinc metal removal by recycled alum sludge, Wat. Res. 33 (1999), pp. 3019-3025.

[8] P. Brown, I.A. Jefcoat, D. Parrish, S. Gill and S. Graham, Evaluation of the adsorptive capacity of peanut hull pellets for heavy metals in solution, Adv. Environ. Res. 4 (2000), pp. 19-29.

[9] C.V. Diniz, F.M. Doyle and V.S.T. Ciminelli, Effect of $\mathrm{pH}$ on the adsorption of selected heavy metal ions from concentrated chloride solutions by the chelating resin dowex M-4195, Sep. Sci. Technol. 37 (2002), pp. 3169-3185.

[10] M. Arias, M.T. Barral and J.C. Mejuto, Enhancement of coper and cadmium adsorption on kaolin by the presence of humic acids, Chemosphere 48 (2002), pp. 1081-1088.

[11] R. Sublet, M.O. Simonnot, A. Boireau and M. Sardin, Selection of an adsorbent for zinc removal from drinking water by a point-of-use treatment device, Wat. Res. 37 (2003), pp. 4904-4912.

[12] B. Biskup and B. Subotic, Removal of heavy metal ions from solutions using zeolites. III. Influence of sodium ion concentration in the liquid phase on the kinetics of exchange processes between cadmium ions from solution and sodium ions from zeolite A, Sep. Sci. Technol. 39 (2004), pp. 925-940.

[13] Q. Li, S. Wu, G. Liu, X. Liao, X. Deng, D. Sun, Y. Hu and Y. Huang, Simultaneous biosorption of cadmium (II) and zinc (II) ions by pretreated biomass of phanerochaete chrysosporium, Sep. Purif. Technol. 34 (2004), pp. 135-142.

[14] F. Ekmekyapar, A. Aslan, Y.K. Bayhan and A. Cakici, Biosorption of copper(II) by nonliving lichen biomass of cladonia rangiformis hoffm, J. Hazard. Mater. 137 (2006), pp. 293-298.

[15] G. P. Rao, C. Lu and F. Su, Sorption of divalent metal ions from aqueous solution by carbon nanotubes: A review, Sep. Purif. Technol.34 (2007), pp 224-231.

[16] M, A. Atieh, F. Ahmadun, C. Guan, E. Mahdi and A. Rinaldi. Effect of Reaction Temperature On The Production Of Carbon Nanotube. NANO: Brief Reports and Reviews Vol. 1, No. 3 (2006) 251-257

[17] F. A. Abuilaiwi, T. Laoui, M. Al-HArthi and A. A. Mautaz "Modification and Functionalization of Multiwalled Carbon Nanotube (MWCNT) Via Fischer Esterification" The Arabian Journal for Science \& Engineering 35, 1C, (2010) P. 37

Dr. Muataz Ali Atieh has an extensive research work in the area of Nanoscience and Nanotechnology, and specifically in synthesis of carbon nanotubes (CNTs), carbon nanofibers(CNFs), Carbon black, whiskers, spiral Carbon nanotues, twisted Carbon nanotubes , carbon nanoporous ball, metal oxide nanoaprticle and nanocatalyst. Dr. Muataz established a research unit in Nanotechnology called NanoCarbon Research Unit (NCRU) in the department of chemical engineering at King Fahd University for Petroleum and Minerals. Five sub research groups have been formed under NCRU, (Nanomaterials Research Group, Nanocomposite Research Group, Nanopolymerization Research Group, Environmental Research Group and Nanodevices Research Group). 